\title{
Synchronous Parotid and Thyroid Gland Metastases from Breast Cancer
}

\author{
Yasemin B. Cihan ${ }^{a}$ Kemal Deniz ${ }^{b} \quad$ Mehmet S. Yilmaz \\ aDepartment of Radiation Oncology, Kayseri Training and Research Hospital, \\ ${ }^{b}$ Department of Pathology, Erciyes University Hospital, \\ 'Department of Radiology, Kayseri Training and Research Hospital, Kayseri, Turkey
}

\section{Keywords}

Breast neoplasm - Metastasis · Parotid - Thyroid . Synchronous neoplasms

\section{Summary}

Background: Metastases to the parotid and thyroid glands from breast cancer are rare and have a poor prognosis. Case Report: We present the case of a patient with breast carcinoma and synchronous involvement of both the parotid and thyroid gland, and review the literature on this subject. Conclusion: Metastatic malignancy in clinically suspect thyroid and parotid nodules could be detected more frequently with routine use of fine needle aspiration biopsy.

\section{Introduction}

Metastasis to the head and neck region, including the parotid and thyroid glands (PTG), are rare. Besides, metastases from distant sites to the PTG can present diagnostic problems and lead to management dilemmas $[1,2]$. In clinical series, renal, lung, and breast carcinomas are frequent sources of PTG metastasis [3, 4]. The incidence of such metastases differs from primary lesions depending on the type of material analyzed. Immunohistochemical staining of tissue sections has improved the differential diagnosis in these lesions. Fine needle aspiration (FNA) and histopathology of tru-cut biopsies can be important tools in establishing the correct diagnosis, and also allow the distinction between potential primary tumors [3]. Here, we present a case of PTG swelling in a female patient with known breast cancer. Relevant histopathological and immunohistochemical features of breast cancer metastasis to the PTG will be discussed.

\author{
Schlüsselwörter \\ Neoplasie der Brust - Metastasierung · Parotis . \\ Schilddrüse $\cdot$ Synchrone Neoplasie
}

\section{Zusammenfassung}

Hintergrund: Metastasierung eines Mammakarzinoms in die Parotis und Schilddrüse ist selten und mit einer schlechten Prognose verbunden. Fallbericht: Wir berichten von einer Patientin mit einem Mammakarzinom und synchronem Befall der Parotis und der Schilddrüse. Desweiteren wird eine Übersicht über die relevante Literatur gegeben. Schlussfolgerung: Metastasen in klinisch auffälligen Parotis- bzw. Schilddrüsenknoten könnten durch routinemäßige Anwendung der Feinnadelbiopsie häufiger erkannt werden.

\section{Case Report}

In 2005, a 70-year-old woman presented with a left-sided breast lump. Excisional biopsy showed a ductal carcinoma. Radical mastectomy was performed. Pathology showed a grade II, invasive ductal carcinoma pT2 $(3 \times 2.5 \mathrm{~cm})$ with $\mathrm{N}_{3}(12 / 16)$ metastatic spread to the axillary lymph nodes. Estrogen and progesterone receptors were strongly positive (+++), and $\mathrm{C}$-erbB $\mathrm{B}_{2}$ was negative in the immunohistochemical analysis. Postoperatively, the patient received 6 cycles of adjuvant chemotherapy. Later, the patient was treated with a 5-week course of radiotherapy (50 Gy/2 fractions) and was started on anastrozole.

Eighteen months later, the patient complained of a swelling and pain in the left parotid gland region, which had persisted for the last 2 months. There was no history of fever, and no correlation between the swelling and food ingestion. On examination, a solitary diffuse swelling of approximately $2 \times 2 \mathrm{~cm}$ was present on the left side of the parotid region. The swelling was firm, non-tender, and fixed to underlying structures. There was no focal nerve palsy. A neck computed tomography (CT) and ultrasound examination showed a node of $2 \mathrm{~cm}$ in the parotid gland, hypodense multiple nodes in the thyroid gland, and 2 suspicious ipsilateral neck lymphadenopathies (fig. 1A). Her complete hematological findings,

\section{KARGER}

Fax +497614520714

Information@Karger.de

www.karger.com (c) 2011 S. Karger GmbH, Freiburg

$1661-3791 / 11 / 0062-0133 \$ 38.00 / 0$

Accessible online at:

www.karger.com/brc
Yasemin Benderli Cihan, MD

Department of Radiation Oncology

Kayseri Training and Research Hospital

Kayseri, Turkey

Tel. +90 352 3-368884/(ext) 1800, Fax -20 7313, H/P -536 2169987

cihany@erciyes.edu.tr 
biochemical profile, and chest radiograph were normal. Cancer antigen (CA) 15-3 was high, carcinoembryonic antigen (CEA) was normal. Metastasis to the thyroid and parotid gland was confirmed by FNA cytology (fig. 2 A).

A combination of total thyroidectomy and parotidectomy with elective neck dissection was recommended but the patient refused. A superficial lobe parotidectomy was performed (fig. 1B). Microscopical analysis of the parotid gland showed ductal adenocarcinoma of the breast metastatic to the superficial lobe of the parotid gland, cytological features consistent with metastases from breast cancer (fig. 2 B). Immunohistochemical examination indicated a negative result for $\mathrm{C}$-erbB $\mathrm{B}_{2}$. However, strong staining was observed with estrogen (fig. 2 C). Postoperatively, whole-neck external beam irradiation at a dose of $50 \mathrm{~Gy} / 25$ fraction/5 week using $6 \mathrm{MV}$ photons was given to the patient. She was also investigated for other sites for metastatic disease. A whole-body bone scan showed bone metastases, and abdominal ultrasound revealed liver involvement. The patient was treated with 8 cycles of paclitaxel $80 \mathrm{mg} / \mathrm{m}^{2}$ once a week, followed by radiotherapy. Later, she refused treatment and was lost to follow-up.

\section{Discussion}

Metastases to the PTG rarely arise from cutaneous sites of the head and neck but predominantly from infraclavicular tumors. Most metastases migrate through either the lymphatics or the blood stream, except for the parotid gland [1-3]. The average survival after diagnosis is $6-9$ months. There are individual differences in the metastatic spread of neoplasms to the PTG, which are very important for therapeutic and prognostic reasons [3-6].

Signs and symptoms of metastatic tumors are similar to those of primary tumors. Most clinical metastases in the PTG present as solitary nodules. Most thyroid and parotid metastases are discovered during routine follow-up physical examinations or imaging studies after resection of the primary tumor [1-5]. In our case, the patient presented with a palpable mass. She had undergone a mastectomy 18 months earlier, and the parotid and thyroid mass was the first presenting symptom.
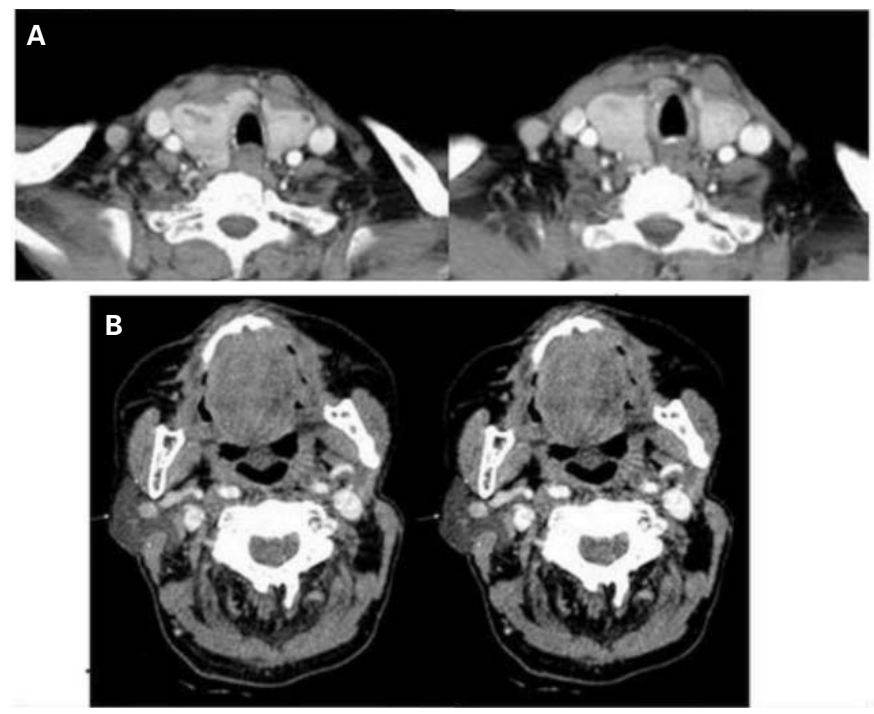

Fig. 1. A Computed tomography scan revealing enhancing masses in the thyroid gland; B CT scan revealing a superficial lobe parotidectomy.
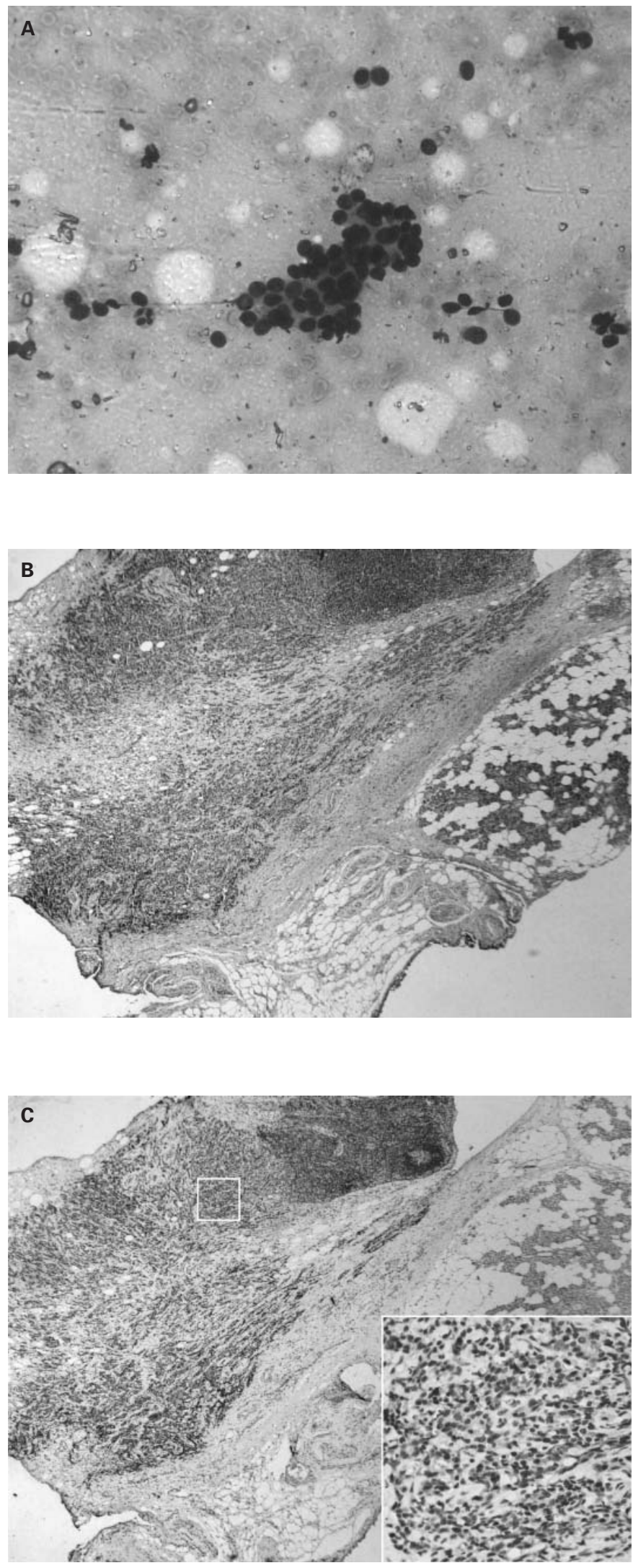

Fig. 2. A Malignant tumor infiltrating the thyroid acini (S stained; $\times 400$ ); B Section showing ductal adenocarcinoma of the breast metastatic to the superficial lobe of the parotid gland ( $\mathrm{H}$ and $\mathrm{E} ; \times 40)$; C Immunochemistry for estrogen showing strong positivity on metastatic cells to the parotid gland $(\mathrm{E} ; \times 40)$. 
Metastatic disease involving the PTG may be a diagnostic problem. It may be evident upon palpation, ultrasonography, Doppler ultrasonography, CT or magnetic resonance imaging, and visible in the histopathological examination. In general, however, in metastatic PTG swelling, an FNA could accurately confirm a clinical suspicion of metastasis with low morbidity [4-6]. In the present case, the metastatic lesion was diagnosed by FNA cytology, supported by a biopsy from the breast.

Although the optimal therapy sequence is unknown, treatment of PTG metastatic disease is a combination of surgical removal of solitary tumors, chemotherapy, and radiation therapy [2, 6, 7]. Our patient refused the recommended surgical treatment plan and was treated with a superficial lobe parotidectomy, followed by adjuvant radiotherapy and chemotherapy.

Estrogen and progesterone receptor determination is helpful in defining the primary tumor [7]. In our case, histologic sections from a mastectomy specimen and an excisional biopsy from the parotid gland mass were compared. We compared findings of hematoxylin-eosin and various immunohistochemical stains, also of the parotid gland after parotidectomy. The comparison showed the immunohistochemical features were very important to make an accurate diagnosis as in our case [7].

Almost all current therapeutic modalities for metastatis to the PTG in the presence of disseminated disease are palliative. Current immunohistochemical markers have improved the distinction between a number of potential primary tumors. Accordingly, the diagnosis of metastatic breast carcinoma may require histochemical and immunohistochemical as well as clinical information. In any patient with a previous history of malignancy, a new thyroid and/or parotid mass should be considered as a metastasis until proven otherwise.

\section{Disclosure Statement}

None of the authors have a substantial direct or indirect commercial financial incentive associated with the publication of the article. There is no source of extra-institutional funding for this study.

\section{References}

1 Bissett D, Bessell EM, Bradley PJ, Morgan DA, et al.: Parotid metastases from carcinoma of the breast. Clin Radio 1989;40:309-310.

2 Nakhjavani MK, Gharib H, Goellner JR, van Heerden JA: Metastases to the thyroid gland. A report of 43 cases. Cancer 1997;79:574-578.

-3 Kim TY, Kim WB, Gong G, et al.: Metastasis to the thyroid diagnosed by fineneedle aspiration biopsy. Clin Endocrinol 2005;62:236-241.

4 Ménégaux F, Chigot JP: Thyroid metastases. Ann Chir 2001;126:981-984.

5 Bron LP, Traynor SJ, McNeil EB, O’Brien CJ: Primary and metastatic cancer of the parotid: comparison of clinical behavior in 232 cases. Laryngoscope 2003;113:1070-1075.

6 Lam KY, Lo CY: Metastatic tumors of the thyroid gland: a study of 79 cases in Chinese patients. Arch Pathol Lab Med 1998;122:37-41.

7 Perez-Fidalgo JA, Chirivella I, Laforga J, Colio JM, et al.: Parotid gland metastasis of a breast cancer. Clin Transl Oncol 2007;9:264-265. 